\title{
Cost Analysis of Therapeutic Interchange of Calcium Channel Blockers for the Treatment of Hypertension: Unexpected Results from a Conversion Program
}

\begin{abstract}
OBJECTIVE: To examine drug expenses and overall health care resource utilization associated with a calcium channel blocker therapeutic interchange and conversion program.
\end{abstract}

DESIGN: A pre/post analysis involving a retrospective cohort study design and primarily using administrative databases was done. The study was conducted from an institutional perspective using hospital-specific drug acquisition costs in 1997 dollars.

SETIING: Veterans Administration Hospital, Saginaw, Michigan.

PATIENTS: One hundred and one patients receiving extended-release nifedipine (Procardia $X L$ ) were converted to either amlodipine (Norvasc) or felodipine (Plendil) through the institution's conversion program.

MAIN OUTCOME MEASURES: Change in total drug cost, secondary health resource utilization, study drug costs, cardiovascular drug costs, noncardiovascular drug costs, change in severity of hypertension.

RESULTS: Unexpectedly, the total cost of drug therapy was significantly higher during the nine-month postconversion period relative to the nine-month preconversion period $(p<0.001)$.
Neither the total number of clinic visits nor the number of hospitalizations (cardiovascular or noncardiovascular) differed significantly between the preconversion and postconversion periods. No significant differences in the grade of hypertension was observed from the preconversion period to the postconversion period, although there were statistically significant drops in both systolic (mean reduction of $7.5 \mathrm{~mm} \mathrm{Hg}$; $p<0.001$ ) and diastolic blood pressures (mean reduction of $5.6 \mathrm{~mm} \mathrm{Hg} ; p<$ 0.001).

CONCLUSIONS: The increased drug expenses and significant change in blood pressure appear to have been due to an increased number of prescriptions filled in the postconversion period relative to the preconversion period. Further study is warranted to determine whether this unexpected finding was due to a pharmacological factor such as improved tolerability of the medications or to an effect of the process of conversion itself.

KEYWORDS: Cost, therapeutic interchange, calcium channel blockers, hypertension

J Managed Care Pharm 2000: 390-394

\section{Authors}

MUHAMMAD M. MAMDANI, Pharm.D., is a scientist at the Institute for Clinical Evaluative Sciences and Assistant Professor of Pharmacy at the University of Toronto, in Toronto, Canada, CHRISTINA J. REISIG, R.Ph., is Assistant Chief of Pharmacy Services, Saginaw Michigan Veterans Administration Hospital in Saginaw, MI; JAMES G. STEVENSON, Pharm.D., is Director of Pharmacy Services, University of Michigan Health System in Ann Arbor, MI. At the time of this study Drs. Mamdani and Stevenson were with the Wayne State University College of Pharmacy and Detroit Medical Center.

AUTHOR CORRESPONDENCE: James G. Stevenson, Pharm. D., Department of Pharmacy Services, University of Michigan Hospitals, 1500 East Medical Center Dr. Ann Arbor, M1 48109-0008; Phone: 734-647-7794; Fax: 734-936-7027; E-mail: jimsteve@umich.edu.

ACKNOWLEDCEMENT: This study was partially funded through an unrestricted educational grant from Astra-Merch, linc.

Copyright 1000 Academy of Managed Care Pharmacy, Inc. All rights reserved.

\section{A}

by Muhammad M. Mamdani, Christina J. Reisig, and James G. Stevenson

sons are not controlling their blood pressure to below $140 / 90 \mathrm{~mm} \mathrm{Hg}$ as recommended by the Sixth Report of the Joint National Committee on the Prevention, Detection, Evaluation, and Treatment of High Blood Pressure (JNC-6)., ${ }^{1,2}$ When considering pharmacologic therapy, the optimal formulation should provide 24-hour efficacy with a once-daily dose. Such long-acting formulations are preferred over short-acting agents for many reasons:

- Adherence is better with once-daily dosing.

- For some agents, fewer tablets mean lower costs.

- Control of hypertension is persistent and smooth.

- Protection is provided against risk of sudden death, heart attack, and stroke caused by the abrupt increase of blood pressure after one rises from overnight sleep. ${ }^{2}$

Long-acting calcium channel blocking agents such as extended release nifedipine (Procardia XL), amlodipine (Norvasc), and felodipine (Plendil) belong to the dihydropyridine family and are regarded as effective second-line agents for the treatment of hypertension. ${ }^{3.4}$ Because of the demands of the health care environment, cost of therapy must be considered when selecting between similar agents. Studies have been conducted to assess the feasibility of converting patients from the more-expensive extended-release nifedipine to the less-expensive and perhaps equally effective felodipine or amlodipine..$^{5-7}$

Given these positive findings, hospitals have used this strategy in attempts to lower costs. A cost-minimization approach to such initiatives is typically sufficient when assessing drugs of the same class, although questions commonly arise concerning whether the changes in drug therapy associated with a therapeutic interchange program result in other changes in health care resource utilization. Clinic visits and hospitalizations, among other factors, should be considered in addition to drug costs in assessing the true overall impact.

We conducted a retrospective cohort study using an administrative database to assess the health resource utilization implications of a formulary switch program at a Veteran's Administration (VA) hospital that mandated conversion from extendedrelease nifedipine (Procardia XL) to either amlodipine (Norvasc) or felodipine (Plendil). We speculated that a cost-minimization 


\section{Cost Analysis of Therapeutic Interchange of Calcium Channel Blockers for the Treatment of Hypertension: Unexpected Results from a Conversion Program}

analysis examining total drug costs would be sufficient because no significant differences in outcomes with respect to clinic visits or hospitalizations as a result of the conversion program were expected.

\section{Methods}

\section{Study Design}

A pre/post analysis involving a retrospective cohort study design and primarily using the administrative databases of the VA hospital in Saginaw, Michigan, was conducted to assess the resource utilization implications of a calcium channel blocker therapeutic interchange program. The study was conducted through an institutional perspective and hospital-specific drug acquisition costs in 1997 dollars were used. While 1997 dollars were used for standardization, actual costs of the study drugs varied by less than $3 \%$ from these values during the study period. The Saginaw VA Hospital is a 250-bed hospital with associated ambulatory clinics primarily serving veterans.

All patients at the Saginaw VA Hospital receiving extendedrelease nifedipine (Procardia XL) were converted to either amlodipine (Norvasc) or felodipine (Plendil) from September 1994 through February 1.995. The study drugs were defined as extended-release nifedipine, amlodipine, and felodipine. The conversion date was defined as the first record of a filled prescription for either amlodipine or felodipine. Patients eligible for study inclusion were defined as all patients continuously serviced by the VA Hospital with at least nine months of complete data prior to and also following the conversion date with respect to drug utilization, clinic visits, and hospitalizations, and a documented diagnosis of hypertension by International Classification of Diseases, 9th Revision (ICD-9), code. All eligible patients must have also been receiving Procardia XL throughout the analysis period prior to the conversion date.

One hundred and one patients were identified from the database. Patient charts were reviewed for blood pressure readings during the most recent clinic visit prior to the conversion date and also the final clinic visit following the conversion date but prior to the end of the study period. If more than one blood pressure reading was recorded, an average of the readings available was calculated. The patients were assigned classifications of hypertension according to JNC-6.

The primary economic endpoint of interest was the change in total drug cost. Secondary health resource utilization endpoints to justify a cost-minimization approach were the number of clinic visits, emergency room visits, and hospitalizations during the pre- and post-conversion periods. Secondary economic endpoints of interest were the study drug costs, cardiovascular drug costs, and noncardiovascular drug costs during the pre- and postconversion periods. Cardiovascular drugs were defined as those drugs belonging to any of the following drug classes: (1)
TABLE 1 Patient Demographics

\begin{tabular}{l|c}
\hline Sample size & 101 \\
\hline Median age (interquartile range) & $68(12.8)$ \\
\hline Gender, number of males & 100 \\
\hline Race' (\%) & 81 \\
White & 14 \\
African American & 5 \\
Other & 58 \\
\hline Hypertension grade & 33 \\
1 & 10 \\
2 & \\
3 & Race distribution was based on data available for 42 patients. \\
\hline
\end{tabular}

vasodilators, (2) angiotensin-converting enzyme (ACE) inhibitors, (3) alphaz-agonists, (4) alpha1-antagonists, (5) other calcium channel blockers, (6) diuretics, and (7) beta-blockers. The primary clinical endpoint of interest was the change in the severity of hypertension as defined by classification of hypertension according to JNC-6. Changes in systolic and diastolic blood pressure were also assessed from the pre-to post-conversion periods.

\section{Patient Demographics}

The patient population consisted of a total sample size of 101 predominantly male patients. The median age of the population was 68 years; the majority of patients were white and were classified as having grade 1 or grade 2 hypertension (see Table 1 , above).

\section{Statistical Analysis}

The paired sample $t$-test was used to test for significant differences in continuous variables between the pre- and post-conversion periods. McNemar's test was used to test for differences in discrete variables. To contrast resource utilization between patients of differing grades of hypertension, differences were assessed using one-way analysis of variance. Tukey's honestly significant difference test was selected as the post-hoc test to contrast these differences between the groups.

\section{Results}

\section{Study Drug Characteristics}

During the preconversion period, the median prescribed daily dose of extended-release nifedipine was $60 \mathrm{mg}$ (interquartile range [IQR]=30; see Table 2, page 392). Twenty-nine percent of patients were converted exclusively to amlodipine and $62 \%$ of patients were converted exclusively to felodipine during the post-conversion period (Table 2). Among patients receiving 


\section{TABLE $2 \longdiv { \text { Study Drug Characteristics } }$}

Study Drug Acquisition Cost

Nifedipine

$\begin{array}{lr}30 \mathrm{mg} & \$ 0.634 \\ 60 \mathrm{mg} & 1.135 \\ 90 \mathrm{mg} & 1.365\end{array}$

Amlodipine

$\begin{array}{rr}2.5 \mathrm{mg} & \$ 0.633 \\ 5 \mathrm{mg} & 0.621 \\ 10 \mathrm{mg} & 1.135\end{array}$

Felodipine

$\begin{array}{rr}2.5 \mathrm{mg} & \$ 0.48 \\ 5 \mathrm{mg} & 0.48 \\ 10 \mathrm{mg} & 0.48\end{array}$

Patients Receiving Dose of Extended-Release Nifedipine throughout Preconversion Period

\begin{tabular}{cr}
$30 \mathrm{mg}$ & 36 \\
$60 \mathrm{mg}$ & 34 \\
$90 \mathrm{mg}$ & 19 \\
$120 \mathrm{mg}$ & 1 \\
Mixture & 11 \\
\hline
\end{tabular}

Study Drug Conversion of Patients throughout PostConversion Period

\begin{tabular}{cc}
\hline To amlodipine, $\mathrm{n}=29^{1}$ & \\
$2.5 \mathrm{mg}$ & 1 \\
$5 \mathrm{mg}$ & 11 \\
$10 \mathrm{mg}$ & 10 \\
Multiple & 7
\end{tabular}

To felodipine, $\mathrm{n}=63^{1}$

$\begin{array}{rr}2.5 \mathrm{mg} & 0 \\ 5 \mathrm{mg} & 19 \\ 10 \mathrm{mg} & 29 \\ 15 \mathrm{mg} & 3 \\ \text { Multiple } & 12\end{array}$

'Nine patients were tried on sequential combinations of amlodipine and felodipine.

exclusively amlodipine or felodipine during the post-conversion period, the median daily doses were the same (median $=10$ $\mathrm{mg}, \mathrm{QQR}=5$ ). The proportion of subjects receiving once-daily dosing using one tablet per administration was significantly lower during the post-conversion period $(95 \%$ vs. $83 \%$, $p<0.01$ ).

\section{Primary Economic and Health Resource Utilization Endpoints}

The total cost of drug therapy rose by an average of approximately $\$ 176$ per patient during the nine-month post-conversion period relative to the nine-month preconversion period (see Table 3, page 393; $p<0.001$ ). The total number of clinic visits, emergency room visits, and hospitalizations was not significantly different between the two study periods (Table 3 ).

\section{Primary Clinical Endpoints}

No significant differences were noted in the classification of hypertension among patients from the pre- to the post-conversion period $(p=0.734)$. There were, however, statistically significant drops in both systolic and diastolic blood pressures. Systolic blood pressure dropped from a mean of $157.03 \mathrm{~mm} \mathrm{Hg}$ $(S D=15.59)$ in the preconversion period to $149.52 \mathrm{~mm} \mathrm{Hg}$ $(\mathrm{SD}=17.58)$ in the post-conversion period, for an average reduction of $7.5 \mathrm{~mm} \mathrm{Hg}(\mathrm{SD}=1.99 ; p<0.001)$. Similarly, diastolic blood pressure dropped from a mean of $86.92 \mathrm{~mm} \mathrm{Hg}(S D=10.53)$ to $81.32 \mathrm{~mm} \mathrm{Hg}(\mathrm{SD}=5.60)$, for an average reduction of $5.6 \mathrm{~mm} \mathrm{Hg}$ $(\mathrm{SD}=1.46 ; p<0.001)$

When assessing the differences between the groups with regard to classification of hypertension, significant reduction in systolic blood pressure was greater for grades 2 and 3 patients relative to grade 1 patients (mean differences of $15.55 \mathrm{~mm} \mathrm{Hg}$ and $23.77 \mathrm{~mm} \mathrm{Hg}$ for grades 2 and 3, respectively; $p$ values are $<0.001$ and 0.001 , respectively).

\section{Secondary Economic Endpoints}

The study drug cost rose significantly during the post-conversion period relative to the preconversion period, by an average of approximately $\$ 45$ per patient ( $p<0.001$; see Table 4, page 393). This was consistent with a significant rise of 1.38 prescriptions per patient during the post-conversion period relative to the preconversion period ( $p<0.001$; Table 4 ) and a modest yet significant rise in the number of prescribing physicians per patient.

A nonsignificant increase in the number of patients receiving cardiovascular medications from 58 in the preconversion period to 64 in the post-conversion period was observed $(p=0.180)$. Cost of cardiovascular drug therapy, however, rose significantly by an average of approximately $\$ 50$ per patient in the cohort ( $p=0.002$; Table 4 ) as did the average number of prescriptions per patient for these medications (average increase of 3.4 prescriptions; $p<0.001$; Table 4).

The number of patients receiving other medications increased significantly from 93 in the preconversion period to 99 in the post-conversion period $(p=0.031)$. The cost of other drug therapy also rose significantly, by an average of approximately $\$ 98$ per patient during the same period ( $p<0.001$; Table $4)$. The average number of other drug prescriptions per patient rose by $5.9(p<0.001$; Table 4$)$.

\section{Discussion}

In organized health care systems, formularies are widely used to improve the quality of drug therapy and control costs. Frequently, when there are several similar agents in a therapeu- 
Cost Analysis of Therapeutic Interchange of Calcium Channel Blockers for the Treatment of Hypertension: Unexpected Results from a Conversion Program

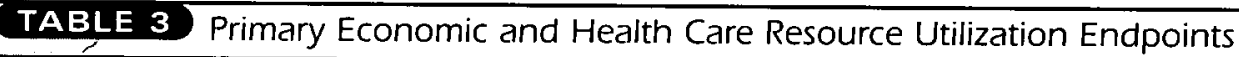

\begin{tabular}{|c|c|c|c|}
\hline & Preconversion & Post-conversion & $p$ value \\
\hline $\begin{array}{l}\text { Total drug utilization } \\
\text { Mean cost/patient (SD) } \\
\text { Mean difference/patient } \\
\text { Mean number of prescriptions/patient (SD) }\end{array}$ & $\begin{array}{r}\$ 323.68(215.83) \\
11.24(14.75)\end{array}$ & $\begin{array}{r}\$ 499.42(332.73) \\
\$ 175.74(280.66) \\
20.70(26.09)\end{array}$ & $<0.001$ \\
\hline $\begin{array}{l}\text { Clinic visits } \\
\text { Mean number of visits (SD) } \\
\text { Mean difference }\end{array}$ & $13.3(10.3)$ & $\begin{array}{r}14.1(1.1 .3) \\
0.82(10.89) \\
\end{array}$ & 0.450 \\
\hline $\begin{array}{l}\text { Emergency room visits } \\
\text { Mean number of visits (SD) } \\
\text { Mean difference } \\
\text { Patients requiring emergency visits }\end{array}$ & $\begin{array}{r}0.72(2.35) \\
13\end{array}$ & $\begin{array}{r}0.24(0.80) \\
-0.49(2.45) \\
9\end{array}$ & $\begin{array}{l}0.051 \\
0.481\end{array}$ \\
\hline $\begin{array}{l}\text { Hospitalizations } \\
\text { Mean number of hospitalizations (SD) } \\
\text { Mean difference } \\
\text { Patients requiring hospitalizations }\end{array}$ & $\begin{array}{r}0.22(0.61) \\
14\end{array}$ & $\begin{array}{r}0.21(0.55) \\
-0.01(0.59) \\
15\end{array}$ & $\begin{array}{l}0.870 \\
1.000\end{array}$ \\
\hline
\end{tabular}

\section{TABLE 4 Secondary Economic Endpoints}

\begin{tabular}{|c|c|c|c|}
\hline & Preconversion & Post-conversion & $p$ value \\
\hline $\begin{array}{l}\text { Study drug } \\
\text { Mean cost/patient (SD) } \\
\text { Mean difference } \\
\text { Tablets/patient (SD) } \\
\text { Mean difference } \\
\text { Number of prescriptions per patient (SD) } \\
\text { Mean difference } \\
\end{array}$ & $\begin{array}{r}\$ 174.39(95.33) \\
180.34(88.66) \\
1.9(1.72)\end{array}$ & $\begin{array}{r}\$ 219.46(126.26) \\
\$ 45.07(138.36) \\
370.21(214.50) \\
189.86(225.30) \\
3.28(1.69) \\
1.38\end{array}$ & $\begin{array}{l}<0.001 \\
<0.001\end{array}$ \\
\hline $\begin{array}{l}\text { Cardiovascular drugs } \\
\text { Mean cost/patient (SD) } \\
\text { Mean difference } \\
\text { Number of prescriptions/patient (SD) } \\
\text { Mean difference }\end{array}$ & $\begin{array}{r}\$ 40.63(74.88) \\
2.82(4.05)\end{array}$ & $\begin{array}{r}\$ 90.65(137.35) \\
\$ 50.02(127.22) \\
6.24(10.09) \\
3.41(7.00)\end{array}$ & $\begin{array}{r}0.002 \\
<0.001\end{array}$ \\
\hline $\begin{array}{l}\text { Other drugs } \\
\text { Mean cost/patient (SD) } \\
\text { Mean difference } \\
\text { Number of prescriptions/patient (SD) } \\
\text { Mean difference }\end{array}$ & $\begin{array}{r}\$ 124.40(154.00) \\
7.59(10.34)\end{array}$ & $\begin{array}{r}\$ 222.66(228.42) \\
\$ 98.27(186.63) \\
13.48(17.15) \\
5.90(10.27)\end{array}$ & $\begin{array}{l}<0.001 \\
<0.001\end{array}$ \\
\hline $\begin{array}{l}\text { Prescribing physicians } \\
\text { Mean number of prescribing physicians (SD) } \\
\text { Mean difference }\end{array}$ & $2.06(1.29)$ & $\begin{array}{l}2.56(1.37) \\
0.50(1.60)\end{array}$ & 0.002 \\
\hline
\end{tabular}

tic class, a system will select one or two agents as the preferred drugs for most patients. The selection of these preferred agents is frequently made in favor of those presumed to result in the lowest daily drug costs. Typically this is done by estimating the equivalent doses that will be required to produce the same therapeutic effect and calculating the daily costs of these agents. In most cases it is assumed that other health care costs will remain unchanged. However, some have questioned whether savings in drug costs may be offset by other costs that may be associated with the conversion process. These might include increased clinic visits, hospitalizations, or emergency room visits to have dosages retitrated, or exposing patients to new agents that might produce unwanted effects.

This phenomenon was studied in the Saginaw VA hospital, 


\section{Cost Analysis of Therapeutic Interchange of Calcium Channel Blockers for the Treatment of Hypertension: Unexpected Results from a Conversion Program}

which had attempted to reduce drug costs by changing the preferred extended-release calcium channel blocking agent from nifedipine (Procardia XL) to amlodipine or felodipine. The presumed daily costs of the latter two agents were less than nifedipine and they were presumed to result in similar therapeutic effects in the management of hypertension.

Despite the fact that at projected doses it was anticipated that study drug costs would be reduced post-conversion, the costs were actually $\$ 45 /$ patient greater after converting to amlodipine or felodipine. One explanation for this result could be that larger than projected doses of amlodipine or felodipine were necessary to produce blood pressure control. The dosing schedule and number of tablets per administration will undoubtedly affect costs given the separate costs/tablet. Using fewer tablets and daily administration times leads to lower costs. The proportion of subjects receiving once-daily dosing using one tablet per administration was significantly lower during the post-conversion period.

A greater factor in the increased study drug costs is the fact that patients received 1.38 more prescriptions in the post-conversion period compared with the preconversion period. The precise reason for this difference cannot be explained by the retrospective methods employed in this study. It is possible that patients and physicians were more conscientious about monitoring of hypertension following the conversion simply because there was a change in the therapy.

The cost of other cardiovascular drug therapy also increased by approximately $\$ 50 /$ patient during the post-conversion period, as did the mean number of prescriptions, by 3.4. Again, it is difficult to sufficiently explain why this increase was observed given the problems associated with conducting extensive subanalyses on such limited data.

The cost of other drugs (noncardiovascular) increased in the post-conversion period by $\$ 98$ and the number of prescriptions increased by 5.9 per patient. Furthermore, the total drug therapy costs were greater in the nine-month post-conversion period by $\$ 176$ per patient. Again, we speculate that these differences may be explained by a form of Hawthorne effect resulting from a change in the drug regimen.

Interestingly, both systolic and diastolic blood pressure were significantly lower in the post-conversion period. Systolic blood pressure dropped by $7.5 \mathrm{~mm} \mathrm{Hg}$ and diastolic by $5.6 \mathrm{~mm} \mathrm{Hg}$. However, there were no significant changes in the classification of hypertension among the cohort of patients between the preconversion and postconversion periods.

Since other studies have demonstrated that the agents involved in the conversion have similar effects on blood pressure, this gives credence to the hypothesis that the actual process of conversion led to increased monitoring and adherence to the drug regimen. The effects of extraneous factors on blood pressure, such as the nonsignificant increase in other cardiovascular medication use in the postconversion period, are largely unknown and may have contributed to our observations.

No significant differences were noted in clinic visits, emergency room visits, or hospitalizations between the preconversion and post-conversion periods. Therefore, there were no "hidden" costs of conversion due to increased health care utilization related to retitration or adverse events, and a cost-minimization analysis examining only total drug costs was justified.

\section{Conclusion}

This study demonstrated that patients may be safely converted from extended-release nifedipine to amlodipine or felodipine. Blood pressure reductions were greater post-conversion in this group of patients, although it is uncertain whether these reductions would be sustained in the long term. In addition to the unexpected greater reduction in blood pressure post-conversion, there were also greater costs associated with study medications, other cardiovascular medications, and other noncardiovascular medications. The increased costs were primarily attributable to a greater number of prescriptions for these agents being filled post-conversion.

Other clinical studies have not demonstrated differences in blood pressure reduction or control between these agents at equivalent doses. ${ }^{8}$ This suggests that the process of conversion itself may have resulted in a form of Hawthorne effect, in which the change in drug therapy itself resulted in improved monitoring and patient adherence with the new regimen. Only a longer-term analysis would answer the question of whether this reduction in blood pressure and increase in compliance would be sustained.

\section{References}

1. Burt VL, et al. Prevalence of hypertension in the U.S. adult population: results from the third National Health and Nutrition Examination Survey, 1988-91. Hypertension 1995; 25: 305-13.

2. Sixth Report of the Joint National Committee on Prevention, Detection, Evaluation and Treatment of High Blood Pressure. National Institutes of Health: National Heart, Lung, and Blood Institute. Publication Number 98 4080. November 1997.

3. Salerno SM, Zugibe FT. Calcium channel antagonists: what do the second generation agents have to offer? Postgrad Med 1994; 95: 181-88.

4. Koeing W. Efficacy and tolerability of felodipine and amlodipine in the treatment of mild to moderate hypertension. Am J Cardiol 1992; 69: 271-14

5. Gustin $G$, et al. Clinical outcome of a mandatory formulary switch for dihydropyridine calcium channel blocker therapy at a Veteran's Administration medical center. Am J Hyperten 1996; 9: 312-16.

6. Landry FJ, et al. Felodipine as an alternative to more expensive calcium channel antagonists in mild to moderate hypertension. South Med J 1996;89 (6): $573-77$

7. Markakis EC, Schepers GP. Nifedipine GITS to amlodipine conversion in a pharmacist-staffed VA hypertension ciinic. P\&T 1999; 1: 37-45.

8. Lefebvre J, et al. Comparative effects of felodipine ER, amlodipine and nifedipine GITS on 24-hour blood pressure control and trough-to-peak ratios in mild to moderate ambulatory hypertension: a forced titration study. Can J Cardiol 1998; 14: 682-88. 